\title{
O direito processual civil na pós-modernidade a partir da obra \\ “O Processo" de Franz Kafka: a necessidade de superação da ideia de processo como mero instrumento.
}

Jaqueline Mielke Silva ${ }^{1}$

\section{Resumo:}

O direito processual civil contemporâneo atravessa duas grandes crises. A celeridade do processo é uma delas, considerando o grande número de processos que atualmente tramitam. A segunda diz respeito à efetividade, pois, de nada adianta um processo rápido, se ao final o autor da ação não consegue a realização do seu respectivo direito. Franz Kafka na obra "O Processo", previu esta crise, principalmente a partir da estrutura e funcionamento do poder judiciário exposta. É preciso adequar o Direito Processual Civil à realidade social contemporânea, de modo que os direitos sejam efetivados, superando-se, assim, a ideia de processo prevista por Franz Kafka.

Abstract:

The contemporary civil procedural law faces two major crises. One of them is the speed of the process, considering the large number of cases currently which are being dealt. The second relates to effectiveness, because a quick process can be a totally non sense, if at the end the plaintiff fails to carry out their respective right. Franz Kafka has predicted predicted this crisis, especially from the point of view of the structure and function of the Courts. We must adapt the Civil Procedure Law to the social reality, on way to get them effective, overcoming thus the idea of process provided by Franz Kafka.

\section{A crise do poder judiciário prevista por Franz Kafka.}

Uma das maiores deficiências de nosso tempo é o desinteresse pela atividade política e a má compreensão do que ela vem a ser. Dissociou-se a sociedade do Estado, o econômico do político e o individual do social. A atividade política pode ser entendida como algo específico de um segmento da sociedade profissionalizado para isso. A desvalia do político foi acentuada nas últimas décadas, quando o autoritarismo militar criminalizava a atuação política dos outros segmentos sociais e desqualificava a formação política dos brasileiros. A desqualificação do político leva à desqualificação do indivíduo como cidadão,

\footnotetext{
${ }^{1}$ Professora da disciplina de Direito Processual Civil I, do Cesuca, Doutora em Direito. 
acentuando no Direito sua face de pura dominação, antes que seu caráter de resultante da livre interação dos segmentos sociais por meio da ação de seus atores.

Considerando a realidade social acima exposta, o Direito Processual Civil contemporâneo passa por duas grandes crises. A primeira delas diz respeito ao número de processos e, a segunda, é relacionada à efetividade do processo. A alta conflituosidade existente na sociedade contemporânea faz com que o judiciário se torne insustentável, principalmente se levarmos em consideração às demandas de massa.

E impossível dentro da estrutura atualmente existente no âmbito do poder judiciário, principalmente no âmbito da jurisdição de segundo grau, que os processos sejam devidamente analisados. E foi justamente essa situação que foi prevista por Franz KAFKA, na obra "O Processo".

Na obra "O Processo", Joseph K. não sabe os motivos de sua acusação. Por outro lado, não sabe exatamente quem o acusou. Se não bastasse ignorar as razões pelas quais foi preso, no final, é executado por dois agentes, que também não são identificados, que o arrastam para um lugar quase deserto e lhe enfiam no peito um facão de açougueiro.

A partir do exposto, observa-se que ninguém analisou o caso de Joseph K.! Lamentavelmente, essa é a situação existente hoje no âmbito do poder judiciário. Os processos não conseguem ser sequer lidos, que dirá analisados!

Nas ações de massa - que envolvem relações conflituosas semelhantes - a situação é ainda mais grave, pois os advogados "recortam e colam" petições iniciais, os réus "recortam e colam" as contestações e os magistrados "recortam e colam as decisões". Se houver alguma peculiaridade que difere a demanda de outra, NINGUÉM certamente se dará conta, por uma simples razão: os processos não têm condições de serem devidamente analisados. Foi exatamente o que aconteceu com Joseph K!

$\mathrm{Na}$ verdade, pode-se dizer que Franz KAFKA, na obra "O Processo" previu precisamente o que aconteceria no âmbito do poder judiciário na pós-modernidade. $\mathrm{O}$ grande mérito da obra é que o autor visualizou toda a crise pela qual atualmente atravessamos há quase cem anos atrás

Diante do contexto que atualmente vivemos, é inegável que o Direito Processual Civil está em descompasso com a realidade contemporânea, em que pese termos alguns exemplos de tentativa de adequação.

Temos um modelo de processo elaborado a partir das teorias que sustentaram a modernidade. Todavia, a sociedade se transformou. Vivemos hoje em uma sociedade 
globalizada. Portanto, o que talvez pudesse ser perfeitamente compatível com a era moderna, apresenta seríssimos problemas com o atual momento que estamos vivenciando, a chamada pós-modernidade, idealizada por Franz KAFKA. É preciso (re) construir o Direito Processual Civil a partir da sociedade em que atualmente vivemos. Para isso, é preciso reconhecer que ele está adaptado a uma tradição da era moderna e que, por esta razão, é imperfeito e insuficiente para resolver os conflitos que emergiram nesta nova era.

Precisamos criar mecanismos de modo a que os processos sejam efetivamente analisados, considerando-se que o Direito Processual Civil não é um fim em si mesmo, mas um instrumento de realização de direitos.

\section{A comunicação entre o Direito Processual Civil e o mundo da vida:}

\section{Realidade Social x Instrumentalidade.}

O Direito Processual Civil moderno deve ser o resultado da prática do mundo cotidiano. Ele não pode estar em uma "estratosfera" distante do mundo da vida. De nada adianta o Processo, se ele não é capaz de solucionar os impasses do mundo cotidiano. Evidentemente, que o modelo narrado na obra de Franz Kafka, atualmente vivenciado na sociedade contemporânea, não serve! Neste sentido, a procedimentalização é fundamental para o desenvolvimento da própria sociedade. Todavia, ela apenas tem razão de existir se o seu sentido for a pacificação social. J. J. CALMON DE PASSOS ${ }^{2}$, ao tratar do tema, refere:

\footnotetext{
“O processo de produção do Direito, por conseguinte, é sempre dependente da realidade social que busca ordenar e a ela funcionalmente se vincula, objetivando emprestar-lhe segurança, mediante a predeterminação e institucionalização de modelos ou esquemas de solução de conflitos coercitivamente aplicáveis aos casos concretos.

Somente se pode falar em uma real pacificação social, se tivermos um Direito Processual Civil adequado à realidade moderna, e não a outros momentos históricos. Assim, podemos ter mecanismos processuais ainda vigentes, que talvez muito tenham servido no passado - em determinado momento histórico por nós vivenciado - mas que hoje estão absolutamente superados. Um destes exemplos é o nosso moroso procedimento ordinário. Neste aspecto, imperioso o estudo da tradição e de seus reflexos na legislação. Apenas é possível compreender o sistema jurídico, se conhecemos as razões históricas que inspiraram sua formulação. A partir deste conhecimento, é possível - então - a verificação se ele continua, ainda, adequado (ou não) à nova realidade social em que se propõe aplicá-lo".
}

\footnotetext{
${ }^{2}$ In: PASSOS, J. J. Calmon de. Direito, Poder, Justiça e Processo - Julgando os que nos julgam, p. 93. 
Alasdair MACINTYRE ${ }^{3}$, ao tratar deste tema, refere que:

\begin{abstract}
"A pessoa fora de todas as tradições carece de recursos racionais suficientes para a pesquisa, e, a fortiori, para a pesquisa sobre qual tradição deve ser racionalmente preferida. Essa pessoa não tem os meios relevantes adequados de avaliação racional, e, portanto, não pode chegar a nenhuma conclusão bem-fundamentada, incluindo a conclusão de que nenhuma tradição pode se defender contra qualquer outra. Estar fora de todas as tradições significa ser estranho à pesquisa; significa estar num estado de destituição moral e intelectual, uma condição a partir da qual é impossível formular a objeção relativista".
\end{abstract}

O Direito Processual Civil deve ser o resultado de uma razão comunicativa, extraída a partir da praxis cotidiana ${ }^{4}$, tanto no aspecto legislado quanto no referente ao direito interpretado pelos Tribunais. Neste aspecto, a análise do discurso jurídico se torna imprescindível $^{5}$. Ninguém duvida que a prática do Direito consista, fundamentalmente, em argumentar. A teoria da argumentação jurídica tem como objeto de reflexão as argumentações deduzidas em contextos jurídicos ${ }^{6}$. Em princípio, podem-se distinguir três diferentes campos jurídicos em que ocorrem argumentações ${ }^{7}$. O primeiro é o da produção ou estabelecimento de normas jurídicas. Um segundo campo em que se efetuam argumentos jurídicos é o da aplicação de normas jurídicas à solução de casos, embora essa seja uma atividade levada a cabo por juízes em sentido estrito, por órgãos administrativos no sentido mais amplo da expressão ou por simples particulares. O terceiro âmbito em que se verificam argumentos jurídicos é o da dogmática jurídica. Segundo Manuel ATIENZA ${ }^{8}$,

"A dogmática é, sem dúvida, uma atividade complexa, na qual cabe distinguir essencialmente as seguintes funções: 1) fornecer critérios para a produção do

\footnotetext{
${ }^{3}$ In: MACINTYRE Alasdair. Justiça de quem? Qual Racionalidade?, p. 394.

${ }^{4}$ Ver capítulos 4 e 5.

5 Jürgen HABERMAS (In: La ética del discurso y la cuestión de la verdad. Madrid: Paidós, 2003, p. 34), defende "la racionalidad comunicativa combinada con un modelo holista de justificación (véase Verdad y Justificación.Traducción de Pere Fabra y Luis Díez. Madrid: Editorial Trotta, 2002, p. 32-62), ...”.

6 "Sobretodo en el campo de los juicios morales y de los problemas prácticos en general, la necessidad de ponerse de acuerdo en un procedimiento salta a la vista ante la proliferación de códigos de conducta y la falta de argumentos concluyentes a los que apelar. Al afirmar esto se está postulando la necesidad de un modelo articulado de racionalidad procedimental que establezca las condiciones con arreglo a las cuales deba desenvolverse el procedimiento argumentativo, pues sin un modelo tal no es factibile determinar la validez de una conclusión normativa. Lo que determina el mérito y valor de una norma carece de sustancialidad y depende, en definitiva, del propio procedimiento de fundamentación. La posición habermasiana al respecto es que sólo cabe hablar de consenso racional - como fundamento de validez de un enunciado normativo - si dicho consenso ha sido logrado en unas circunstancias que satisfacen, al menos, de modo aproximado, las condiciones de simetría y libertad propias de una situación ideal de habla. (In: VELASCO ARROYO Juan Carlos. La teoría discursiva del derecho - sistema jurídico y democracia en Habermas, p. 75).

${ }^{7}$ In: ATIENZA, Manuel. As razões do Direito - Teorias da Argumentação Jurídica, p. 18-9.

${ }^{8}$ In: ATIENZA, Manuel. As razões do Direito - Teorias da Argumentação Jurídica, p. 19.
} 
Direito nas diversas instâncias em que ele ocorre; 2) oferecer critérios para a aplicação do Direito; 3) ordenar e sistematizar um setor do ordenamento jurídico."

Argumentos $^{9}$ em prol da legitimidade do direito devem ser compatíveis com os princípios morais da justiça e da solidariedade universal ${ }^{10}$ - sob pena de dissonâncias cognitivas - bem como com os princípios éticos ${ }^{11}$ de uma conduta de vida autoresponsável, projetada conscientemente, tanto de indivíduos, como de coletividades $^{12}$. Jürgen HABERMAS $^{13}$ designa, como morais, todas as instituições que nos informam sobre as melhores formas de nos comportarmos, "para que possamos reagir, mediante a deferência e a consideração, à extrema vulnerabilidade dos indivíduos". Ninguém pode afirmar por si próprio a sua integridade. A integridade da pessoa individual reclama a estabilização de um tecido de relações simétricas de reconhecimento, no qual os indivíduos inalienáveis, só reciprocamente, e enquanto membros de uma comunidade poderão assegurar sua precária identidade. A moral visa à fragilidade crônica da integridade pessoal, que é intrínseca à estrutura das interações lingüisticamente mediadas e que precede ainda a vulnerabilidade tangível da integridade corporal, apesar de se entrecruzar com esta. ${ }^{14}$

É óbvio que esta distinção entre integridade pessoal e corporal desaparece no caso dos animais, uma vez que não imputamos personalidade a seres com os quais não podemos falar ou comunicar sobre algo no mundo. As interações entre homens e animais são mediadas por gestos não-lingüísticos, e o mal que o homem possa causar ao animal não atinge algo de idêntico a uma identidade pessoal ${ }^{15}$.

\footnotetext{
9"En todo caso, fundamentar un enunciado normativo es una cuestión racional. Fundamentar algo es dar razón de algo, y esto nos revela la estructura intrínsecamente comunicativa de cualquier fundamentación. 'Habermas ha definido la racionalidad humana como comunicación: fundamentación racional de algo significa que la verdad o la rectitud de algo puede ser defendida con argumentos, de cualquier tipo que éstos sean, en un diálogo con cualquier potencial oponente' (...). En el terreno que aquí nos interessa, el de la fundamentación racional de esfera de lo práctico, Habermas ha señalado que 'deber hacer algo implica tener buenas razones para hacer algo." (In: VELASCO ARROYO Juan Carlos. La teoría discursiva del derecho - sistema jurídico y democracia en Habermas, p. 75).

${ }^{10}$ Vide capítulo 4.

${ }^{11}$ Sobre o tema, vide também: MACINTYRE, Alasdair. História de la Ética. Buenos Aires: Paidos.

${ }^{12}$ In: HABERMAS, Jürgen. Direito e Democracia - entre facticidade e validade, v. I, p. 132-3.

${ }^{13}$ In: HABERMAS Jürgen. Comentários à Ética do Discurso, p. 18.

${ }^{14}$ In: HABERMAS Jürgen. Comentários à Ética do Discurso, p. 216.

${ }^{15}$ Segundo Jürgen HABERMAS (In: Comentários à Ética do Discurso, p. 219), "a responsabilidade do homem para com as plantas e para com a preservação da espécie na sua totalidade não pode ser fundamentada em termos de deveres interactivos, isto é, sob o ponto de vista moral. No entanto, consigo, na linha de Patzig, conceber perfeitamente que, para além de razões de prudência, existem boas razões éticas que falam a favor da protecção das plantas e das espécies. São razões que nos assaltam quando nos questionamos seriamente acerca do modo como queremos viver neste planeta enquanto elementos de uma sociedade global civilizada, e como queremos, enquanto elementos da nossa espécie, tratar as outras espécies”.
} 
A teoria discursiva possui um conceito amplo de razão prática, que abarca os usos pragmáticos, éticos e morais da mesma ${ }^{16}$. Segundo Juan Carlos Velasco ARROYO ${ }^{17}$,

"La relación existente entre derecho y moral puede definirse, desde a perspectiva habermasiana, como un entrelazamiento complementario. No hay, por tanto, ningún atisbo de subordinación jerárquica del derecho respecto de la moral, sino una común participación el la razón práctica. Ambos sistemas normativos desarrollan juicios y argumentos prácticos a partir de ese tronco común configurado por el principio discursivo. En vez de una relación de supeditación, se establece una relación de complementariedad que no debe asociarse con tesis iusnaturalistas, entre otros motivos porque 'la moral ya no flota sobre o derecho (como todavía sugiere la construcción del derecho natural racional) como conjunto positivo de normas. Emigra al interior del derecho, pero sin agotarse en derecho positivo.

\section{Segundo Luigi Paolo COMOGLIO ${ }^{18}$,}

“... quest'ultima impone di considerare come dovuto (e cioè: come due, debido o
devido) non già qualunque processo che si limite ad essere estrinsecamente fair (vale
a dire: correto, leale o regolare, sul piano formale, secondo la law of the land), bensì
um processo che sia intrinsecamente equo e giusto, secondo i parametri etico-morali
accetatti dal comune sentimento degli uomini di qualsiasi epoca o paese, in quanto si
riveli capace di realizzare una giustizia veramente imparziale, fondata sulla natura e
sulla ragione. Da Qui traggono origine le postulazioni teoriche, ormai quasi
dovunque condivise, per la promulgazione e l'adozione di solenni atti legislativi
(nazionali od internazionali) che riconoscano a tutti gli individui, in termini effettivi
e senza irrazionali discriminazioni, il diritto fondamentale as un processo equo e
giusto, quale nucleo essenziale del più ampio diritto ad un ordinamento giuridico
giusto."

O autor supra transcrito ressalta a importância dos aspectos éticos, bem como da justiça do procedimento. Um processo civil justo e 'social' deve fundamentar-se no reconhecimento de amplos os poderes discricionários em poder do juiz ${ }^{19}$.

Interpretar e aplicar o Direito obriga sempre a um balanceamento entre o geral e o singular, entre o texto passado da norma e a exigência presente da justiça ${ }^{20}$. Atender ao

\footnotetext{
${ }^{16}$ In: VELASCO ARROYO Juan Carlos. La teoría discursiva del derecho - sistema jurídico y democracia en Habermas, p. 99.

17 VELASCO ARROYO Juan Carlos. La teoría discursiva del derecho - sistema jurídico y democracia en Habermas, p. 106.

18 In: COMOGLIO, Luigi Paolo. Valori etici e ideologie del 'giusto processo' (modelli a confronto). Rivista Trimestrale di Diritto e Procedura Civile. Milano, v. 52, n. 3, p. 887-938, set. 1998, p. 899.

${ }^{19}$ Sobre o tema, vide: CHELI Enzo. Princìpi e ideologie del processo civile: impressioni di un 'revisionista'. Rivista Trimestrale di Diritto e Procedura Civile, v. 57, n. 2, p. 575-82, jugno. 2003, p. 577.

${ }^{20}$ Segundo Jürgen HABERMAS (In: Comentários à Ética do Discurso, p. 19), “em sentido moderno, a justiça diz respeito à liberdade subjectiva de indivíduos inalienáveis; em contrapartida, a solidariedade prende-se com o bem-estar das partes irmanadas numa forma de vida partilhada intersubjectivamente. Frankena fala do principle of justice, o princípio do igual tratamento, e do principle of benevolente, que nos obriga a fomentar o bem-estar geral. A ética do discurso explica por que razão estes dois princípios remontam à mesma raiz da moral nomeadamente à vulnerabilidade, carente de compensação, revelada pelos seres vivos, que só se particularizam
} 
chamado da justiça exige a recriação da norma contida no texto legal, não somente no sentido de que toda leitura/interpretação jurídica deve atender à singularidade de cada caso. Neste sentido, uma prática interpretativa que adote os princípios morais e éticos pode ajudar a superar a indeterminação dos enunciados jurídicos ${ }^{21}$. Não se trata de uma interpretação dirigida a uma resposta certa ${ }^{22}$, mas uma interpretação comprometida com a busca da justiça e o caráter aberto, intangível desta. Os princípios morais e éticos não funcionariam com sentido único e decisivo, mas apenas como orientação à atividade do julgador.

\section{A necessidade de adequação do Direito Processual Civil à realidade social} contemporânea.

Ao lado das preocupações com a moral e ética que o Direito Processual Civil deve ter como escopo, um dos grandes problemas contemporâneos é o da duração do processo. $\mathrm{O}$ número de demandas aumenta vertiginosamente a cada dia. A inadequação dos instrumentos processuais faz com que a prestação jurisdicional seja demorada. Ora, prestar jurisdição tardiamente significa o mesmo que não prestá-la.

Pelo exposto, é preciso que seja estabelecida esta atividade dialógica entre o Direito Processual Civil e o mundo da vida, implementando-se instrumentos diferenciados, capazes de torná-lo mais ágil e efetivo. Ao tratar do tema, refere Nicolò TROCKER ${ }^{23}$ :

"Ligado ao contraste entre o garantismo formal que abre abstratamente os mecanismos processuais a quem quer pretenda recorrer ao juiz para a defesa das

em indivíduos por acção da socialização, de modo que a moral, ao defender os direitos do indivíduos, é obrigada a defender igualmente o bem- estar da comunidade a que o mesmo pertence".

${ }^{21}$ Ver capítulos 3, 4 e 5.

${ }^{22}$ Segundo Juan Carlos ARROYO (La teoría discursiva del derecho - sistema jurídico y democracia en Habermas, p. 76), "en particular, en relación con el mundo del derecho, este universalismo normativo especialmente atento al contexto de acción implicaría entender (...) la aplicación del derecho como una questión pragmática, forzosamente contingente, que no tiene a priori una respuesta fija, pues siempre han de tenerse en cuenta las circunstancias, tendencias, probabilidades y posibilidades cambiante de cada caso práctico.

23 "Legato al contrasto tra il garantismo formale che apre astrattamente $i$ meccanismi processuali a chiunque intenda far ricorso al giudice per la difesa delle prorpie ragioni, e la realtà dei nostri sistemi processuali - che con la loro complessità e costosità creano severi ostacoli alla realizzazione del diritto -, il problema dell'acesso alla giustiza si manifesta innanzitutto come problema di accesso agli strumenti di tutela giurisdizionale. E come tale esso richiede di trovare una sua prima risposta nell'impegno di istituire appositi strumenti capaci di attenuare gli ostacoli di carattere economico - il costo delle liti - che condizionano la possibilità diperseguire il riconoscimento giudiziale dei diritti. Oggi, tale impegno assume anche una particolare severità di fronte al riconoscimento costituzionale delle garanzie legate al principio del 'giusto processo'.” (In: TROCKER, Nicolò. Acesso alla giustizia e assicurazione legale. Rivista Trimestrale di Diritto e Procedura Civile, n. 4, p. 1065-92, dic. 1986, p. 1.066). 
próprias razões, e a realidade dos nossos sistemas processuais - que com a sua complexidade e custos criam obstáculos severos à realização do direito -, o problema de acesso à justiça manifesta-se antes de mais nada como problema de acesso aos instrumentos de tutela jurisdicional. E como tal, este solicita encontrar uma sua primeira resposta no compromisso de instituir adequados instrumentos capazes de atenuar os obstáculos de caráter econômico - o custo dos litígios - que condicionam a possibilidade de perseguir o reconhecimento judicial dos direitos. Hoje, este compromisso assume também uma severidade particular perante o reconhecimento constitucional das garantias ligadas ao princípio do "processo justo."

A partir do exposto, pode-se formular a seguinte equação gráfica:

\author{
Aplicação de princípios morais e éticos
}

$+$

\title{
Agilização na tramitação do procedimento
}

\section{PROCESSO JUSTO}

A equação acima explicitada não significa um abandono a concepções substantivas de justiça, em prol de uma visão procedimental. O que se afirma é que procedimentos justos podem quase sempre produzir decisões justas ${ }^{24}$, independentemente de um apelo ao estabelecimento preciso do que seja a justiça em caráter substantivo ${ }^{25}$. Segundo Willis Santiago GUERRA FILHO,

\footnotetext{
${ }^{24}$ Segundo Juan Carlos Velasco ARROYO (La teoría discursiva del derecho - sistema jurídico y democracia en Habermas, p. 101), "sólo cuando el derecho satisface tanto el principio da positivación como el fundamentación se puede afirmar que se encontra racionalmente asentado. La validez del derecho se basa, pues, tanto en la legalidad - principio de positivación - como en la legalidad - principio de fundamentación (...) El carácter obligatorio del derecho positivo no radica sólo en las propiedades formales que lo caracterizam, sino en la incorporación de propiedades morales. El principio de fundamentación se atiene a razones de índole moral y, en particular, resulta esencial la asunción de un punto de vista general y desinteresado desde el que las cuestiones puedan enjuiciarse con imparcialidad, al que suele denominarse precisamente punto de vista moral. “

${ }^{25}$ Neste sentido: Michel ROSENFELD e Andrew ARATO (In: Habermas on law and democracy - Critical Exchanges. Berkeley: University of California Press, 1998, p. 82-114). Também: KOZICKI Kátia. Conflito e Estabilização: comprometendo radicalmente a aplicação do Direito com a democracia nas sociedades contemporâneas, p. 233.
} 


\begin{abstract}
"A mencionada autonomia do sistema jurídico não há de ser entendida no sentido de um isolamento deste diante dos demais sistemas sociais, o da moral, religião, economia, política, ciência etc., funcionalmente diferenciados, em sociedades complexas como a que há na atualidade. Essa autonomia significa, na verdade, que o sistema jurídico funciona com um código próprio, sem necessidade de recorrer a critérios fornecidos por algum daqueles outros sistemas, aos quais, no entanto, o sistema jurídico se acopla com procedimentos desenvolvidos no seu seio, procedimentos de reprodução jurídica, de natureza legislativa, administrativa, contratual e, principalmente, judicial. Ocorre, então, que em geral os interesses coletivos, conquanto respaldados em normas de nível constitucional, não o são por leis regulamentadoras dos direitos fundamentais, delas advindo, e não é por isso que se vai admitir seu desrespeito. Caberá, assim, ao Judiciário suprir a ausência completa e os defeitos da produção legislativa, no sentido da realização dos chamados 'Direitos fundamentais de terceira geração', ou de 'direitos de solidariedade', precisamente os direitos sociais, econômicos e culturais, relativos à preservação do meio ambiente, das peculiaridades culturais de minorias, étnicas ou 'éticas' etc. Vê-se, portanto, como efetivamente se pode sustentar a tese, talvez a principal, que a mim interessa defender no momento: a de que o Judiciário deve assumir, na atualidade, a posição mais destacada, entre os demais Poderes estatais, na produção normativa. (os grifos são do autor)."
\end{abstract}

No Direito brasileiro, temos experimentado diversas tentativas de "modernização" do Processo Civil. Todavia, elas são incapazes de produzir uma transformação significativa em nossa experiência judiciária, por uma simples e incontestável razão: continuamos legislando baseados no paradigma da modernidade. Sem uma mudança de paradigma, continuaremos a ter "reformas" que são apenas paliativos, que em nada resolvem problemas como a efetividade do processo e a realização do Direito.

\title{
Segundo Ovídio Araújo BAPTISTA DA SILVA ${ }^{26}$,
}

“..., é indispensável, e mais do que indispensável, urgente, formar juristas que não sejam como agora, técnicos sem princípios, meros intérpretes passivos de textos, em última análise, escravos do poder (...), pois o servilismo judicial frente ao império da lei anula o Poder judiciário que, em nossas circunstâncias históricas, tornou-se o mais democrático dos três ramos do Poder estatal, já que, frente ao momento de crise estrutural e endêmica vivida pelas democracias representativas, o livre acesso ao Poder Judiciário, constitucionalmente garantido, é o espaço mais autêntico para o exercício da verdadeira cidadania."

A partir do exposto, é preciso e imprescindível no âmbito da sociedade contemporânea criar um novo direito processual civil, que atente a princípios morais e éticos, realizando/efetivando direito!

\section{REFERÊNCIAS}

${ }^{26}$ In: SILVA, Ovídio Araújo Baptista da. Jurisdição e Execução na Tradição Romano-Canônica, p. 44. 
ATIENZA, Manuel. As razões do Direito - Teorias da Argumentação Jurídica, p. 18-9. São Paulo: Landy, 2003.

CHELI, Enzo. Princìpi e ideologie del processo civile: impressioni di un 'revisionista'. Rivista Trimestrale di Diritto e Procedura Civile, v. 57, n. 2, p. 575-82, jugno. 2003, p. 577.

COMOGLIO, Luigi Paolo. Valori etici e ideologie del 'giusto processo' (modelli a confronto). Rivista Trimestrale di Diritto e Procedura Civile. Milano, v. 52, n. 3, p. 887-938, set. 1998 , p. 899.

HABERMAS Jürgen. Comentários à Ética do Discurso. p. 18-9, 216, 219. Tradução de G. L. Encarnação. Lisboa: Instituto Piaget, 1999.

.Direito e Democracia - entre facticidade e validade, v. I, p. 132-3. Tradução de Flávio Beno Siebeneichler. Rio de Janeiro: Tempo Brasileiro, 2003.

La ética del discurso y la cuestión de la verdad. Madrid: Paidós, 2003, p. 34),

KAFKA, Franz. O processo. Trad. Modesto Carone. São Paulo: Companhia das Letras, 2005.

KOZICKI, Kátia. Conflito e Estabilização: comprometendo radicalmente a aplicação do Direito com a democracia nas sociedades contemporâneas, p. 233.Tese de doutorado defendida na Universidade Federal de Santa Catarina no ano de 2000.

MACINTYRE Alasdair. Justiça de quem? Qual Racionalidade?, p. 394. Tradução de Marcelo Pimenta. São Paulo: Loyola, 1991.

. História de La Ética.Buenos Aires: Paidos.

PASSOS, J. J, Calmon de. Direito, Poder, Justiça e Processo - Julgando os que não julgam. p.93.Rio de Janeiro: Forense, 1999. 
ROSENFELD, Michel e ARATO, Andrew. Habermas on law and democracy - Critical Exchanges. Berkeley: University of California Press, 1998, p. 82-114).

VELASCO ARROYO Juan Carlos. La teoría discursiva del derecho - sistema jurídico y democracia en Habermas, p. 75-6, 99, 101, 106. 